\title{
Contaminación bacteriana en concentrados de plaquetas de caballos ${ }^{\#}$
}

\author{
Bacterial contamination in platelet concentrates of horses
}

\author{
ME Álvarez, CE Giraldo, JU Carmona* \\ Grupo de Investigación Terapia Regenerativa, Departamento de Salud Animal, \\ Universidad de Caldas, Manizales, Caldas, Colombia.
}

\begin{abstract}
SUMMARY
The aims of the study were to: 1) assess the risk of bacterial contamination in equine platelet concentrates (PCs) obtained by the tube method under three technical conditions (laminar flow cabinet or in a clean laboratory environment both with burner and without burner) 2) identify the critical points of the process of PCs preparation with risk of bacterial contamination; and 3) identify the potential bacterial contaminants in the process. Bacteriological samples were taken from the skin (shaved or unshaved) of the venipuncture site in 15 horses, both before and after being disinfected; hands and throat of the operator; caps of the tubes where the blood was processed; environment where the equine blood samples were collected; laboratory environment; laminar flow cabinet; bacteriological stove; and PCs obtained under 3 technical conditions. Bacteria were isolated from non-aseptically prepared equine skin, hands and throat of the operator, and the place where the blood samples were taken. Bacteria were not isolated from tube caps, laboratory environment, laminar flow cabinet, or PCs. The isolated bacteria were normal biota from equine skin, human skin and throat, and environmental contaminants. Uncontaminated PCs can be obtained by the tube method in a clean laboratory environment.
\end{abstract}

Palabras clave: plaquetas, contaminación bacteriana, equinos.

Key words: platelet, bacterial contamination, equine.

\section{INTRODUCCIÓN}

Existe un uso creciente de terapias (biofármacos) autólogas basadas en células o en factores de crecimiento como tratamiento de afecciones crónicas degenerativas del aparato locomotor equino (Sutter 2007, Carmona y Prades 2009). Afecciones tales como la osteoartritis, tendinopatía del flexor digital superficial y la desmopatía del ligamento suspensorio han sido tratadas con concentrados autólogos de plaquetas (APCs) (Waselau y col 2008, Carmona y col 2009a,b, Carmona y Prades 2009), aspirados de medula ósea (Hertel 2001) y con células madre (Smith y col 2003). Se han descrito tres métodos generales para preparar APCs equinos: automatizado (aféresis) (Carter y col 2003), semiautomatizado "técnicas buffy coat" (Sutter y col 2004, Schnabel y col 2007) y manual (método del tubo) (Argüelles y col 2006, Carmona y col 2008). Para cada uno de los métodos propuestos se ha reportado el número de plaquetas, leucocitos y los niveles de algunos factores de crecimiento en los APCs. Algunos de los métodos semiautomatizados existentes y el método del tubo se han usado clínicamente en caballos con lesiones del aparato locomotor (Waselau y col 2008, Carmona y col 2009 ${ }^{\mathrm{a}, \mathrm{b}}$, Carmona y Prades 2009).

Aceptado: 21.10.2009.

\# $\quad$ Financiado por la Vicerrectoría de Investigaciones y Postgrados de la Universidad de Caldas, Manizales, Caldas, Colombia.

* Departamento de Salud Animal, Universidad de Caldas, Calle 65 No26-10, Manizales, Caldas, Colombia; carmona@ucaldas.edu.co
A pesar del uso generalizado de procedimientos terapéuticos autólogos basados en factores de crecimiento, especialmente APCs, para el tratamiento de afecciones degenerativas del aparato locomotor del caballo (Sutter 2007, Carmona y Prades 2009) y de los conocimientos moleculares que justifican su aplicación clínica (Smith y col 2006, Schnabel y col 2007), no existe información sobre los riesgos de contaminación bacteriana durante la preparación de biofármacos autólogos y sobre el riesgo potencial o real de la aplicación de esas sustancias contaminadas, especialmente a nivel articular o en las vainas sinoviales equinas. Los protocolos de obtención y aplicación clínica de los biofármacos autólogos enfatizan la necesidad de realizar tales procedimientos bajo condiciones asépticas extremas (Carmona y col 2009a,b, Carmona y Prades 2009), que exigen el uso de una cámara de flujo laminar. Lo anterior limita la preparación y uso terapéutico de los biofármacos en instituciones clínicas especializadas. Este tipo de restricción no hace recomendable la utilización de terapias regenerativas, especialmente de APCs, en las condiciones normales de campo (Carmona y col 2009 ${ }^{\mathrm{a}, \mathrm{b}}$, Carmona y Prades 2009).

Los objetivos del presente trabajo fueron: 1) evaluar el riesgo de contaminación bacteriana de APCs de caballos obtenidos mediante el método del tubo (Argüelles y col 2006, Carmona y col 2008), bajo tres condiciones técnicas diferentes: obtención en cámara de flujo laminar, obtención en ambiente de laboratorio (cuarto cerrado) con y sin mechero, 2) identificar los puntos críticos del proceso de preparación de los APCs con posibilidad de 
contaminación bacteriana y 3) identificar las bacterias contaminantes durante el proceso. La hipótesis fue que los APCs obtenidos mediante el método del tubo pueden ser preparados en cualquiera de las condiciones técnicas propuestas sin ningún riesgo de contaminación bacteriana.

\section{MATERIAL Y MÉTODOS}

Se evaluó el riesgo de contaminación bacteriana del proceso de preparación de los APCs mediante el método del tubo (Argüelles y col 2006, Carmona y col 2008), desde la recolección de sangre del caballo hasta la obtención final del APC (producto terapéutico) en tres condiciones técnicas diferentes, en un ambiente de laboratorio limpio (Ritter y col 2003) con o sin mechero de Bunsen y bajo cámara de flujo laminar horizontal. El ambiente de laboratorio limpio correspondió a una habitación de $4 \mathrm{~m}^{2}, 18-22{ }^{\circ} \mathrm{C}$ de temperatura ambiental, $70 \%$ de humedad relativa y sin turbulencias de aire. El área limpia tenía un mesón de acero inoxidable, paredes y techos pulidos con pintura epóxica, ventanas de vidrio selladas y piso de cerámica, fáciles de limpiar. La habitación fue desinfectada diariamente con hipoclorito de sodio (500 ppm) u otros desinfectantes comerciales.

\section{CABALLOS}

Se emplearon 15 caballos adultos con edad promedio de 14 años (rango: 6-22 años). Los caballos pertenecían a una misma escuela de equitación, por lo que presentaban condiciones sanitarias, de alimentación y manejo similares.

\section{DISEÑO DEL ESTUDIO}

Se tuvieron en cuenta cuatro aspectos inherentes a la preparación de los APCs. Los puntos críticos para cada uno de los aspectos con mayor riesgo de contaminación bacteriana fueron identificados así: 1) Procedimiento técnico: a) desinfección del sitio de la venopunción, con o sin rasurado previo; b) recolección de la sangre al romper la primera barrera de esterilidad de los tubos con citrato de sodio; c) envasado del plasma de primer centrifugado en los tubos sin aditivo recubiertos de silicona. En ese punto se pierde la segunda barrera de esterilidad, puesto que es necesario retirar los tapones de los tubos para el envasado del plasma; d) obtención del concentrado de plaquetas. 2) Operario: a) manos y b) garganta. 3) Caballo: sitio de venopunción. 4) Medio ambiente: se consideró la posible contaminación del producto terapéutico final (APC) con bacterias ambientales, bien fueran del medio ambiente en el que se recolectó la sangre o en las tres condiciones técnicas en las que se prepararon los APCs (numeral 1, literales c y d).
CONTROL DE CALIDAD BACTERIOLÓGICA DEL PROCESO DE OBTENCIÓN Y PREPARACIÓN DE LOS CONCENTRADOS AUTÓLOGOS DE PLAQUETAS

Se realizó toma de muestras (hisopados) seriadas para evaluación bacteriológica desde: 1) La piel de cada uno de los caballos, rasurada y sin rasurar, antes de la desinfección. 2) La piel de cada uno de los caballos (rasurada y sin rasurar), luego de ser desinfectada mediante enjabonado con digluconato de clorhexidina al $0,5 \%$ por 8 minutos, aclaramiento alternado con 10 gasas estériles impregnadas de digluconato de clorhexidina al $0,5 \%$ en solución y 10 gasas estériles impregnadas de alcohol etílico al 70\%, y aclaramiento final con dos gasas estériles impregnadas de solución salina estéril. 3) Previamente se realizó frotis para cultivo de ambas manos del operario y de su garganta. Un solo operario preparó todos los APCs con el objetivo de rastrear (trazabilidad) una posible contaminación del producto final. El operario siempre empleó guantes estériles, gorro y mascarilla quirúrgica durante la venopunción y adicionalmente un delantal quirúrgico estéril durante la obtención de los APCs. 4) Se realizó frotis para cultivo de 180 tapones de los tubos empleados en la toma inicial de sangre y en los que se envasó el plasma de primer centrifugado. 5) Se realizó control microbiológico de ambiente en el lugar de la toma de muestra de sangre de los caballos (a un metro de distancia), en el ambiente de las tres condiciones técnicas evaluadas y en la estufa microbiológica donde se incubaron los cultivos. 6) Finalmente, se realizó control microbiológico de los APCs obtenidos en las tres condiciones técnicas evaluadas. En la figura 1 se presenta una esquematización de los puntos de obtención de las muestras para cultivo bacteriológico.

\section{PROCESO DE OBTENCIÓN Y PREPARACIÓN DE LOS}

CONCENTRADOS AUTÓLOGOS DE PLAQUETAS

Se escogió al azar un lado de la piel del cuello (sitio de venopunción yugular) en cada uno de los caballos para efectuar rasurado o no, en función del experimento propuesto. Las muestras siempre fueron tomadas y analizadas por triplicado en todos los procesos. Se tomaron $162 \mathrm{~mL}$ de sangre a cada uno de los caballos en 36 tubos con citrato de sodio 3,2\% v/v (Vacuette ${ }^{\circledR}$, Greiner Bio-One Vacuette, Capital Drive Monroe, NC, EE.UU.) (4,5 mL de sangre por tubo), para cada yugular se usaron 18 tubos (6 tubos por experimento). Se designó al azar el orden de preparación de los APC en las tres condiciones técnicas de obtención evaluadas. La sangre de ambas venas yugulares de cada uno de los pacientes fue obtenida con un catéter mariposa $21 \mathrm{G}$ (Blood Collection Set, Vacutainer ${ }^{\circledR}$, Franklin Lakes, NJ, EE.UU.). La sangre fue depositada en tubos con citrato de sodio y centrifugados a $120 \mathrm{~g}$ durante 5 minutos. La primera fracción supernadante (50\%) del plasma, adyacente a la capa leucoplaquetaria (buffy coat), 

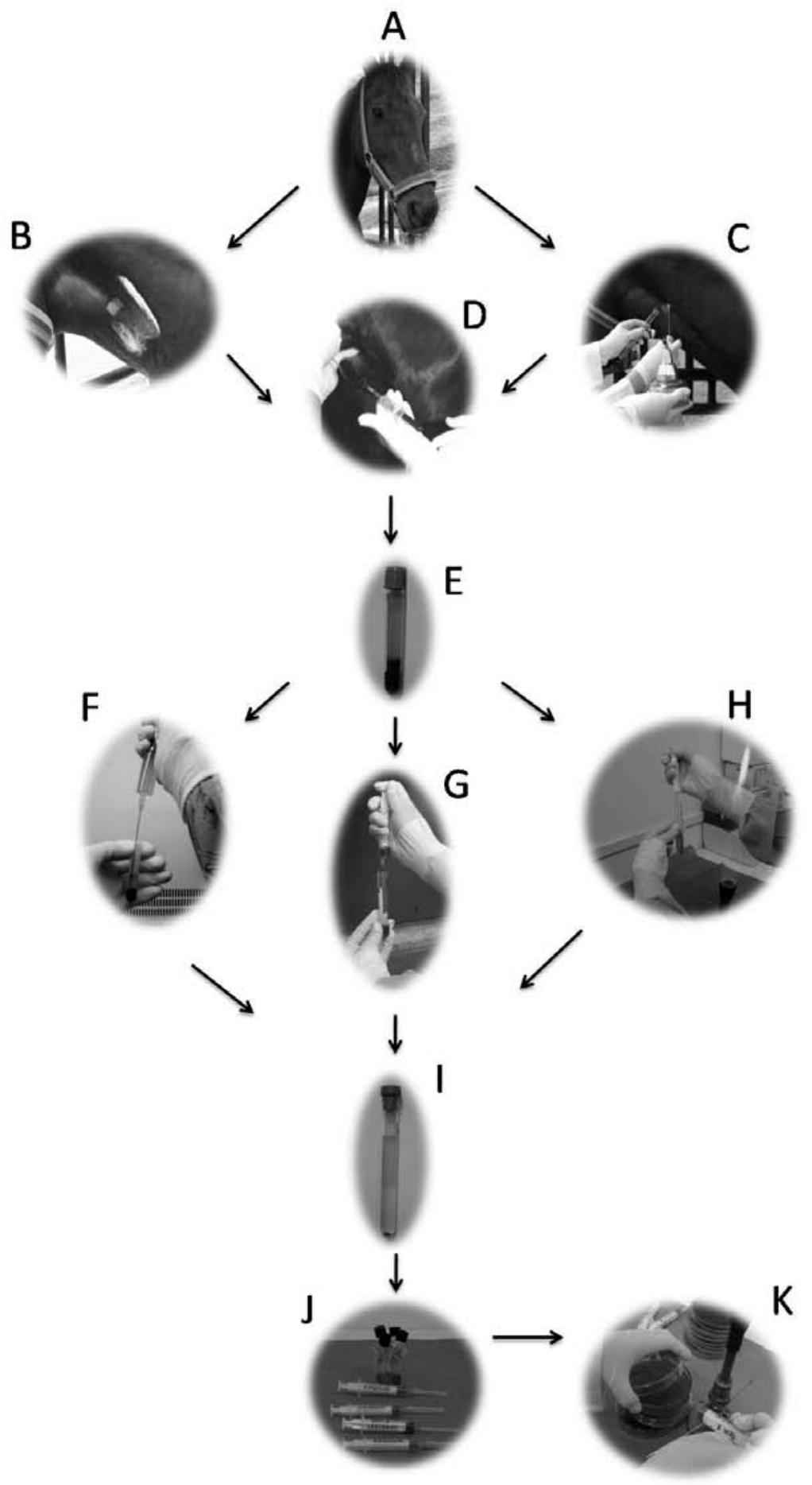

Figura 1. Esquema representativo del proceso de preparación de los concentrados de plaquetas equinas obtenidas mediante el método del tubo en tres condiciones técnicas diferentes. A) Las muestras bacteriológicas fueron tomadas de piel equina sin desinfectar (rasurada o no). B) La piel fue desinfectada (rasurada o no). C) La piel fue muestreada después de la desinfección. D) La sangre fue obtenida mediante venopunción yugular y $\mathbf{E}$ ) depositada en tubos de citrato de sodio. Los concentrados autólogos de plaquetas fueron procesados en una (F) cámara de flujo laminar o en el $(\mathbf{G})$ laboratorio sin mechero o (H) con mechero, (I) mediante segundo centrifugado de plasma equino. J) y K) los concentrados autólogos de plaquetas fueron sembrados en los diferentes medios de cultivo.

Representative scheme of the preparation process of the equine autologous platelet concentrates obtained by the tube method in three technical conditions. A) Bacteriological samples were taken from equine skin without disinfection (shaved or not). B) The skin was disinfected (shaved or not). C) The skin was sampled after disinfection. D) The blood was obtained by jugular venipuncture and E) deposited in sodium citrate tubes. The autologous platelet concentrates were processed in a (F) laminar flow chamber or in the (G) laboratory without Bunsen burner or (H) with Bunsen burner from (I) equine plasma of the second centrifuged. J) and $\mathbf{K}$ ) the autologous platelet concentrates were cultured on several culture media. 
fue obtenida en cada una de las tres condiciones técnicas evaluadas. Las fracciones obtenidas (según cada caso) fueron depositadas en tubos estériles sin aditivo de 10 mL (BD Vacutainer ${ }^{\circledR}$, BD, Franklin Lakes, NJ, EE.UU.) y centrifugadas a $240 \mathrm{~g}$ durante 5 minutos. Luego se extrajo el $25 \%$ del plasma del fondo de cada uno de los tubos en las tres condiciones técnicas evaluadas.

\section{OBTENCIÓN Y PROCESAMIENTO BACTERIOLÓGICO DE} MUESTRAS DEL OPERARIO

Frotis de garganta: Con la ayuda de un bajalenguas estéril, se visualizó la faringe, se rotó sobre la parte posterior de la faringe un hisopo estéril de manera suave pero firme. La muestra se sembró inmediatamente mediante la rotación de toda la superficie del hisopo sobre el primer cuadrante de inoculación en la placa de agar sangre de cordero al 5\%, luego se extendió con un asa estéril por los tres cuadrantes restantes de la placa y se incubó a $37^{\circ} \mathrm{C}$ en atmósfera de $\mathrm{CO}_{2}(5-10 \%)$ durante 24 horas. Los cultivos negativos se reincubaron hasta 48 horas. El frotis de garganta se realizó para detectar si el operario era portador o no de Streptococcus pyogenes.

Frotis de manos: Se utilizaron tubos tapa rosca con 2 $\mathrm{mL}$ de agua peptonada al $0,1 \%$ como diluyente e hisopos de algodón estériles. Se humedeció el hisopo en el diluyente, se rotó sobre la superficie de la palma de la mano, luego se lavó el hisopo en el diluyente y se drenó el exceso de líquido en la pared del tubo. Se realizó el mismo procedimiento de la zona entre los dedos y bajo las uñas, se repitió la misma operación con la otra mano. Al finalizar el lavado se quebró el palillo del hisopo y se dejó caer la porción con algodón dentro del tubo con diluyente. Con la ayuda de un agitador tipo Vortex se agitaron fuertemente los tubos con el diluyente para lograr un buen lavado de los hisopos. Luego se sembró $0,1 \mathrm{~mL}$ del líquido de lavado en la superficie de una placa con agar sangre de cordero al $5 \%$ y una placa de agar Mac Conkey, mediante un asa de platino en forma de zigzag. Las placas se incubaron a $37^{\circ} \mathrm{C}$ durante 24 horas. La toma de muestra de las manos del operador se realizó para detectar si era portador de Staphylococcus aureus, E. coli y/o coliformes fecales.

El recuento de colonias se realizó al día siguiente de la incubación. Se eligieron las placas de agar sangre que contenían entre 20 y 200 colonias aisladas. Se contaron todas las colonias que mostraron $\beta$-hemólisis. Además, se tuvieron en cuenta las reacciones características de fermentación o no de lactosa de coliformes fecales en agar Mac Conkey. La identificación de todas las colonias se realizó mediante sistemas comerciales Staph API ${ }^{\circledR}$ (bioMérieux, Francia) y Crystal ${ }^{\mathrm{TM}}$ Enteric/Nonfermenter $\left(\mathrm{BBL}^{\mathrm{TM}}, \mathrm{BD}\right.$, Franklin Lakes, NJ, EE.UU.).
OBTENCIÓN Y PROCESAMIENTO BACTERIOLÓGICO DE LAS MUESTRAS DE PIEL DE LOS CABALLOS

Las muestras fueron recolectadas en un tubo estéril con $2 \mathrm{~mL}$ de agua peptonada al 0,1\% como diluyente. El área de venopunción fue muestreada al colocar el hisopo sobre el pelo o en contacto con la piel rasurada, antes y después de la desinfección. Las muestras fueron procesadas una hora después de su recolección. Previa agitación de los tubos se sembró $0,1 \mathrm{~mL}$ de cada una de las muestras en caldo de tioglicolato, agar chocolate enriquecido y agar Mac Conkey. El número de unidades formadoras de colonias por $\mathrm{mL}$ (UFCs/mL) fue determinado mediante siembra en tres líneas en zigzag, en placas de agar sangre de cordero al $5 \%$ con diluciones decrecientes $(0,25,0,1$ y $0,05 \mathrm{~mL})$ del sobrenadante de las muestras homogeneizadas. Las UFCs fueron contadas manualmente después de 24 horas de incubación aeróbica a $37^{\circ} \mathrm{C}$. El máximo crecimiento registrado para cualquier muestra se limitó a $10.000 \mathrm{UFCs} / \mathrm{mL}$ para la dilución máxima (Zubrod y col 2004).

La identificación preliminar de los cultivos positivos se realizó mediante exámenes microscópicos de las colonias teñidas con coloración de Gram y la identificación final mediante la utilización de los sistemas comerciales Crystal $^{\mathrm{TM}}$ Enteric/Nonfermenter ID Kit (BBL ${ }^{\mathrm{TM}}$, BD, Franklin Lakes, NJ, EE.UU.), API ${ }^{\circledR} 20$ Strep, API ${ }^{\circledR}$ Staph y API ${ }^{\circledR}$ Coryne (bioMérieux, Francia).

\section{OBTENCIÓN Y PROCESAMIENTO BACTERIOLÓGICO DE MUESTRAS DE TAPONES DE LOS TUBOS SECOS Y CON ANTICOAGULANTE}

La toma de muestras hasta su siembra fue realizada de la misma manera como fue descrita en el apartado de "toma y procesamiento bacteriológico de muestras del operario". Se sembró $0,1 \mathrm{~mL}$ del líquido de lavado en la superficie de una placa con agar sangre de cordero al 5\%, agar chocolate enriquecido, agar Mac Conkey y caldo de tioglicolato. Las placas se incubaron a $37^{\circ} \mathrm{C}$ durante 24 horas. En caso de encontrar cultivos positivos, las UFCs serían contadas manualmente y el máximo crecimiento registrado para cualquier muestra se limitaría a las placas de agar sangre de cordero al $5 \%$ que presentaran entre 20 y 200 colonias aisladas.

\section{PROCESAMIENTO BACTERIOLÓGICO DE LOS CONCENTRADOS DE PLAQUETAS}

Las muestras fueron procesadas una hora después de su recolección. Luego de homogeneizadas, fueron sembradas con asa calibrada $0,1 \mathrm{~mL}$ de APC en caldo de tioglicolato, agar chocolate enriquecido y agar Mac Conkey. Se sembró una placa de agar sangre de cordero al $5 \%$ con diluciones decrecientes $(0,25,0,1$ y $0,05 \mathrm{~mL})$ del sobrenadante de las muestras homogeneizadas y se incubó a temperatura 
ambiente. El número de UFCs/mL fue determinado mediante siembra en tres líneas en zigzag. Las placas fueron incubadas a $37^{\circ} \mathrm{C}$ durante 24 horas. En caso de encontrar cultivos positivos, las UFCs serían contadas manualmente y el máximo crecimiento registrado para cualquier muestra se limitaría a $10.000 \mathrm{UFCs} / \mathrm{mL}$ para la dilución máxima (Zubrod y col 2004).

\section{OBTENCIÓN Y PROCESAMIENTO BACTERIOLÓGICO DE MUESTRAS DEL AMBIENTE}

Las muestras ambientales fueron tomadas en placas de agar sangre de cordero al 5\%. Las tapas de las placas de Petri fueron retiradas en un $50 \%$ y el agar fue expuesto durante 10 minutos al medio ambiente (sitio de recolección de la sangre, ambiente de laboratorio, estufa de incubación y cámara de flujo laminar). Las placas de Petri con agar sangre fueron colocadas aproximadamente a un metro de distancia del caballo o del operario en el laboratorio según el caso e incubadas por 24 horas en atmósfera aeróbica a $37{ }^{\circ} \mathrm{C}$. La identificación de los cultivos positivos fue realizada mediante los sistemas comerciales anteriormente descritos.

\section{ANÁLISIS ESTADÍSTICO}

Los datos fueron analizados con el programa SPSS 16.0 (SPSS Inc, Chicago IL, EE.UU.). Se realizaron pruebas no paramétricas para muestras no apareadas con el objetivo de conocer las diferencias entre el número de UFCs/mL aisladas en la piel equina intacta, la piel rasurada sin desinfectar y las manos del operario. Puesto que el 60\% de las UFCs/ $\mathrm{mL}$ de la piel equina intacta sin desinfectar fue mayor de 10.000 colonias (valores censurados a la derecha), se asumió 10.000 CFUs/mL como valor máximo de detección en esos casos. Se realizó una prueba de Chi cuadrado para determinar si existían diferencias relacionadas con la distribución de bacterias de la piel equina intacta o la piel rasurada sin desinfectar o entre la mano derecha e izquierda del operario. Sólo se realizó análisis estadístico del número de UFCs/mL en esos puntos, ya que no se presentó crecimiento bacteriano en los demás puntos críticos evaluados. Un valor de $\mathrm{P} \leq 0,05$ fue aceptado como estadísticamente significativo para todas las pruebas.

\section{RESULTADOS}

Se realizaron 2.145 cultivos bacteriológicos y se obtuvieron 116 aislamientos correspondientes a 13 especies de bacterias (cuadro 1). Únicamente crecieron bacterias procedentes de la piel sin desinfectar (rasurada o no) de los caballos, las manos y garganta del operario y del medio ambiente donde se tomaron las muestras de sangre equina. No se detectaron bacterias en la piel desinfectada (rasurada o no) del sitio de venopunción de los caballos, en los tapones, medio ambiente del

Cuadro 1. Bacterias aisladas en muestras de caballos, operador y medio ambiente / Total de muestras estudiadas.

Bacteria isolated from samples of horses, operator and environment / Total samples evaluated.

\begin{tabular}{|c|c|c|c|c|c|c|c|c|}
\hline \multirow[b]{2}{*}{ Género y especie } & \multicolumn{4}{|c|}{ Caballo } & \multicolumn{2}{|c|}{ Operador } & \multirow{2}{*}{$\begin{array}{c}\text { Medio } \\
\text { ambiente }^{1}\end{array}$} & \multirow[b]{2}{*}{$\begin{array}{c}\text { Total de } \\
\text { aislamientos }\end{array}$} \\
\hline & $\begin{array}{c}\text { Piel sin } \\
\text { rasurar y sin } \\
\text { desinfección }\end{array}$ & $\begin{array}{c}\text { Piel rasurada } \\
\text { y sin } \\
\text { desinfección }\end{array}$ & $\begin{array}{c}\text { Piel sin } \\
\text { rasurar y con } \\
\text { desinfección }\end{array}$ & $\begin{array}{c}\text { Piel rasurada } \\
\text { y con } \\
\text { desinfección }\end{array}$ & Garganta & Manos & & \\
\hline Staphylococcus aureus & $4 / 15$ & $3 / 15$ & $0 / 15$ & $0 / 15$ & $0 / 15$ & $5 / 15$ & $0 / 75$ & $12 / 165$ \\
\hline Staphylococcus epidermidis & $8 / 15$ & $9 / 15$ & $0 / 15$ & $0 / 15$ & $0 / 15$ & $9 / 15$ & $0 / 75$ & $26 / 165$ \\
\hline Streptococcus bovis & $1 / 15$ & $0 / 15$ & $0 / 15$ & $0 / 15$ & $0 / 15$ & $0 / 15$ & $0 / 75$ & $1 / 165$ \\
\hline Streptococcus viridans & $3 / 15$ & $4 / 15$ & $0 / 15$ & $0 / 15$ & $15 / 15$ & $0 / 15$ & $0 / 75$ & $22 / 165$ \\
\hline Escherichia coli & $4 / 15$ & $3 / 15$ & $0 / 15$ & $0 / 15$ & $0 / 15$ & $0 / 15$ & $0 / 75$ & $7 / 165$ \\
\hline Enterobacter aerogenes & $1 / 15$ & $0 / 15$ & $0 / 15$ & $0 / 15$ & $0 / 15$ & $0 / 15$ & $0 / 75$ & $1 / 165$ \\
\hline Enterobacter sakazakii & $5 / 15$ & $1 / 15$ & $0 / 15$ & $0 / 15$ & $0 / 15$ & $0 / 15$ & $0 / 75$ & $6 / 165$ \\
\hline Enterococcus faecalis & $0 / 15$ & $2 / 15$ & $0 / 15$ & $0 / 15$ & $0 / 15$ & $0 / 15$ & $0 / 75$ & $2 / 165$ \\
\hline Corynebacterium spp. & $9 / 15$ & $2 / 15$ & $0 / 15$ & $0 / 15$ & $0 / 15$ & $0 / 15$ & $0 / 75$ & $11 / 165$ \\
\hline Acinetobacter baumanii & $1 / 15$ & $0 / 15$ & $0 / 15$ & $0 / 15$ & $0 / 15$ & $0 / 15$ & $0 / 75$ & $1 / 165$ \\
\hline Moraxella spp. & $4 / 15$ & $4 / 15$ & $0 / 15$ & $0 / 15$ & $0 / 15$ & $0 / 15$ & $0 / 75$ & $8 / 165$ \\
\hline Citrobacter freundii & $2 / 15$ & $2 / 15$ & $0 / 15$ & $0 / 15$ & $0 / 15$ & $0 / 15$ & $0 / 75$ & $4 / 165$ \\
\hline Bacillus subtilis ${ }^{2}$ & $0 / 15$ & $0 / 15$ & $0 / 15$ & $0 / 15$ & $0 / 15$ & $0 / 15$ & $15 / 75$ & $15 / 165$ \\
\hline Total de aislamientos & $36 / 195$ & $30 / 195$ & $0 / 195$ & $0 / 195$ & $15 / 195$ & $14 / 195$ & $15 / 975$ & $116 / 2.145$ \\
\hline
\end{tabular}

Potro de contención (dos sitios), laboratorio limpio sin y con mechero de Bunsen y cámara de flujo laminar.

Aislamiento en el potro de contención. 
laboratorio, estufa microbiológica, cámara de flujo laminar y los APCs.

Las bacterias aisladas de la piel rasurada o no, antes de la desinfección, fueron predominantemente microbiota normal (Staphylococcus spp. coagulasa-negativa, Streptococcus spp., Corynebacterium spp., Moraxella spp. y enterobacterias). El número de UFCs/mL encontradas en la piel intacta de los caballos sin desinfectar (10.000, rango: 1.300-10.000 UFCs/mL) fue estadísticamente superior $(\mathrm{P} \leq 0,001)$ que el número de colonias (1.900, rango: 500-9.600 UFCs/mL) halladas en la piel rasurada sin desinfectar. Sin embargo, la distribución de las especies de bacterias aisladas fue similar para la piel rasurada o no sin desinfectar $(\mathrm{P} \leq 0,1)$. No se observó una diferencia estadísticamente significativa para UFCs/ $\mathrm{mL}$ entre la mano izquierda (185, rango: 20-200 UFCs/ $\mathrm{mL}$ ) y la mano derecha (50, rango: $20-200 \mathrm{UFCs} / \mathrm{mL})$ del operario; tampoco se observaron diferencias estadísticamente significativas para la distribución de especies bacterianas entre ambas manos del operario $(P \leq 0,1)$. Las bacterias aisladas de la garganta y manos del operario fueron biota normal. Las bacterias comúnmente halladas en la piel normal y rasurada sin desinfectar de los caballos y en las manos del operario fueron Staphylococcus aureus y Staphylococcus epidermidis. Por otra parte, Streptococcus viridans estuvo presente tanto en la piel normal y rasurada sin desinfectar de los caballos, así como en la garganta del operario.

\section{DISCUSIÓN}

Los resultados demostraron que las fuentes potenciales de contaminación bacteriana de los APCs equinos (procesados bajo tres condiciones técnicas diferentes) fueron la microbiota residente de la piel de los caballos, la microbiota de la garganta y manos del operario y los contaminantes medioambientales del lugar donde se tomaron las muestras de sangre. Aunque no se hallaron bacterias en los APCs equinos evaluados, es posible que el punto más crítico sea la preparación de la piel del sitio de la venopunción, tal como ha sido descrito para los controles de calidad bacteriológico de concentrados de plaquetas en seres humanos (Lee y col 2002, te Boekhorst y col 2005, Walther-Wenke y col 2006). Cabe aclarar que el gel de plaquetas humano tiene efecto antibacteriano in vitro contra Staphylococcus aureus y Escherichia coli. Sin embargo, no es activo contra Klebsiella pneumoniae, Enterococcus faecalis y Pseudomona aeruginosa, además parece ser que el crecimiento de este último patógeno se incrementa con la adición de esa sustancia (Bielecki y col 2007). Un estudio sobre la susceptibilidad in vitro de diferentes bacterias patógenas equinas a los APCs debería ser realizado para ampliar esta clase de conocimiento.

No fue posible hallar alguna publicación relacionada con el control de calidad bacteriológica de APCs empleados para procedimientos de terapia regenerativa (no hematológica) en seres humanos o animales. Tampoco se encontró información relacionada con el control de calidad bacteriológico de aspirados de médula ósea o células mononucleares provenientes de grasa de caballos, empleados como biofármacos regenerativos. Sin embargo, algunos investigadores recomiendan la utilización de antibióticos profilácticos luego de inyectar células mesenquimales expandidas a partir de aspirados de médula ósea equina (Smith y col 2003, Guest y col 2008). Nuestro equipo no recomienda la utilización de antibioterapia profiláctica cuando se usa APCs en terapia autóloga equina (Carmona 2006, Carmona y col 2009a,b), aunque este tema es de gran controversia en clínica humana y veterinaria.

Las bacterias aisladas de la piel de los caballos coincidieron con la microbiota indígena y con algunas bacterias ambientales previamente descritas por Nagase y col (2002) y Zubrod y col (2004). Lo mismo sucedió con las bacterias residentes reportadas para las manos (Pittet y col 1999, Nagase y col 2002) y garganta (Hull y Chow 2007) del operario y para las bacterias ambientales (Zubrod y col 2004) aisladas en el lugar donde se tomaron las muestras de sangre (cuadro 1). Por otra parte, no se observó ninguna diferencia estadísticamente significativa entre la distribución de las diferentes especies bacterianas en la piel equina rasurada o no, tal como fue previamente descrito por Hague y col (1997). Un hallazgo importante fue encontrar en las manos del operario cepas de Staphylococcus epidermidis resistente a antibióticos comúnmente usados en clínica equina (cuadro 1). Indudablemente, el uso de guantes estériles y de una correcta técnica aséptica (Pittet y col 1999) fue útil para prevenir la contaminación de los APCs durante su preparación. Cabe recomendar la desinfección previa de las manos y el uso de guantes estériles (Pittet y col 1999) para prevenir la contaminación de los APCs empleados terapéuticamente en el caballo, especialmente a nivel intrarticular o intrasinovial (Carmona y col 2009a,b). Es importante recordar que recuentos tan bajos como 33 UFCs/mL de Staphylococcus aureus pueden inducir artritis séptica en caballos (Gustafson y col 1989), de esta manera la contaminación bacteriana más insignificante de un APC podría desencadenar serias consecuencias en los tejidos sinoviales inyectados.

En este experimento se comprobó que el rasurado de la piel equina, siempre y cuando sea adecuadamente desinfectada, no es un factor crítico asociado con la contaminación de la sangre obtenida para la preparación de los APCs. Este resultado se puede comparar con los hallazgos del estudio de Hague y col (1997), quienes demostraron en caballos que el rasurado de la piel no es un punto crítico asociado con riesgo de infección articular en sitios de artrocentesis asépticamente preparados. El protocolo de preparación aséptica de la piel equina usado en el presente estudio es frecuentemente empleado por veterinarios de equinos alrededor del mundo (Freeman 2006); aunque otros protocolos de desinfección que 
incluyen povidona-yodo y tintura de yodo combinadas con alcohol etílico o isopropílico también podrían ser empleados con seguridad (Freeman 2006, Hague y col 1997, Zubrod y col 2004) para obtener APCs mediante el método del tubo (Argüelles y col 2006, Carmona y col 2008, Carmona y Prades 2009).

En conclusión, las principales fuentes de contaminación de los APCs equinos obtenidos mediante el método de tubo están representadas (en orden de importancia) por la microbiota bacteriana residente en la piel del sitio de venopunción de los caballos, las bacterias residentes en las manos y garganta del operario y las bacterias contaminantes del medio ambiente donde se efectuó la extracción de la sangre. Un adecuado protocolo de desinfección del sitio de la venopunción, el uso de guantes, mascarilla e indumentaria de bioseguridad por parte del operario y obtener la sangre en un ambiente limpio son medidas necesarias para prevenir la contaminación de APCs equinos obtenidos mediante el método del tubo. La hipótesis de nuestro estudio fue comprobada, puesto que no es necesario utilizar cámara de flujo laminar o mechero de Bunsen para obtener APCs estériles, siempre y cuando el ambiente del laboratorio (o de un cuarto) cumpla con las condiciones especificadas en esta investigación.

\section{RESUMEN}

Los objetivos del estudio fueron: 1) evaluar el riesgo de contaminación bacteriana de concentrados autólogos de plaquetas (APCs) de caballos obtenidos mediante el método del tubo en tres condiciones técnicas diferentes (cámara de flujo laminar y en ambiente de laboratorio limpio con mechero o sin mechero), 2) identificar los puntos críticos del proceso de preparación de los APCs con posibilidad de contaminación bacteriana y 3) identificar las bacterias potencialmente contaminantes en el proceso. Se tomaron muestras bacteriológicas de la piel (rasurada o no) del sitio de venopunción de 15 caballos, antes y después de ser desinfectados; manos y garganta del operario; tapones de los tubos donde se procesó la sangre; medio ambiente donde se tomaron las muestras de sangre, ambiente de laboratorio, cámara de flujo laminar, estufa bacteriológica y de los APCs obtenidos bajo condiciones técnicas. Se aislaron bacterias de la piel equina sin desinfectar, manos y garganta del operario y del lugar donde se tomaron las muestras de sangre. No se aislaron bacterias de los tapones de los tubos, medio ambiente del laboratorio, cámara de flujo laminar, ni de los APCs. Las bacterias aisladas fueron biota normal de la piel equina, de la piel y garganta humana, y contaminantes medioambientales. En conclusión, los APCs pueden ser obtenidos mediante el método del tubo en un ambiente limpio.

\section{AGRADECIMIENTOS}

Los autores agradecen a la TC Claribel Idrobo, Directora de la Escuela de Carabineros Alejandro Gutiérrez, Policía Nacional de Colombia, Manizales, Colombia, y los Intendentes Marín, Marroquín y López, que colaboraron con el manejo de los caballos. También agradecen muy especialmente la colaboración técnica de Catalina López, MVZ.

\section{REFERENCIAS}

Argüelles D, JU Carmona, J Pastor, A Iborra, L Vinals, P Martínez, E Bach, M Prades. 2006. Evaluation of single and double centrifugation tube methods for concentrating equine platelets. Res Vet Sci 81, 237-245.

Bielecki TM, TS Gazdzik, J Arendt, T Szczepanski, W Król, T Wielkoszynski. 2007. Antibacterial effect of autologous platelet gel enriched with growth factors and other active substances: an in vitro study. J Bone Joint Surg Br 89, 417-420.

Carmona JU, D Argüelles, M Prades. 2008. Niveles de factor de crecimiento transformante beta-3 y óxido nítrico en cuatro concentrados autólogos de plaquetas y plasma derivados de sangre equina. Arch Med Vet 40, 155-160.

Carmona JU, D Argüelles, M Prades. 2009a . Concentrados autólogos de plaquetas como tratamiento de lesiones de tejidos blandos del aparato locomotor en caballos. Arch Med Vet 41, 77-82.

Carmona JU, C López, M Prades. 2009 ${ }^{b}$. Uso de concentrados autólogos de plaquetas obtenidos mediante el método del tubo como tratamiento de artropatías en caballos. Arch Med Vet 41, 175-179.

Carmona JU, M Prades. 2009. Platelet concentrates to treat musculoskeletal disease in horses. VDM-Verlag, Saarbrücken, Germany.

Carter CA, DG Jolly, CE Worden, DG Hendren, CJ Kane. 2003. Plateletrich plasma gel promotes differentiation and regeneration during equine wound healing. Exp Mol Pathol 74, 244-255.

Freeman DE. 2006. Sterilization and antiseptics. In: Auer J, Stick J (eds). Equine Surgery. $3^{\text {rd }}$ ed. Saunders Elsevier, St Louis MO, USA, Pp 112-123.

Guest DJ, MR Smith, WR Allen. 2008. Monitoring the fate of autologous and allogeneic mesenchymal progenitor cells injected into the superficial digital flexor tendon of horses: preliminary study. Equine Vet J 40, 178-181.

Gustafson SB, CW McIlwraith, RL Jones. 1989. Comparison of the effect of polysulfated glycosaminoglycan, corticosteroids, and sodium hyaluronate in the potentiation of a subinfective dose of Staphylococcus aureus in the midcarpal joint of horses. Am J Vet Res 50, 2014-2017.

Hague BA, CM Honnas, RB Simpson, JG Peloso. 1997. Evaluation of skin bacterial flora before and after aseptic preparation of clipped and nonclipped arthrocentesis sites in horses. Vet Surg 26, 121-125.

Hertel DJ. 2001. Enhanced suspensory ligament healing in 100 horses by stem cells and other bone marrow components. Proceedings American Association Equine practitioners 47, 319-321.

Hull MW, AW Chow. 2007. Indigenous microflora and innate immunity of the head and neck. Infect Dis Clin North Am 21, 265-282.

Lee CK, PL Ho, NK Chan, A Mak, J Hong, CK Lin. 2002. Impact of donor arm skin disinfection on the bacterial contamination rate of platelet concentrates. Vox Sang 83, 204-208.

Nagase N, A Sasaki, K Yamashita, A Shimizu, Y Wakita, S Kitai, J Kawano. 2002. Isolation and species distribution of staphylococci from animal and human skin. $J$ Vet Med Sci 64, 245-250.

Pittet D, S Dharan, S Touveneau, V Sauvan, TV Perneger. 1999. Bacterial contamination of the hands of hospital staff during routine patient care. Arch Intern Med 159, 821-826.

Ritter M, J Schwedler, J Beyer, K Movassaghi, R Mutters, A Neubauer, N Schwella. 2003. Bacterial contamination of ex vivo processed PBPC products under clean room conditions. Transfusion 43, 1587-1595.

Schnabel LV, HO Mohammed, BJ Millar, WG McDermott, MS Jacobson, KS Santangelo, LA Fortier. 2007. Platelet Rich Plasma (PRP) Enhances anabolic gene expression patterns in flexor digitorum superficialis tendons. J Orthop Res 25, 230-240.

Smith JJ, MW Ross, RK Smith. 2006. Anabolic effects of acellular bone marrow, platelet rich plasma, and serum on equine suspensory ligament fibroblasts in vitro. Vet Comp Orthop Trauma 19, 43-47.

Smith RK, M Korda, GW Blunn, AE Goodship. 2003. Isolation and implantation of autologous equine mesenchymal stem cells from 
bone marrow into the superficial digital flexor tendon as a potential novel treatment. Equine Vet J 35, 99-102.

Sutter WW, AJ Kaneps, AL Bertone. 2004. Comparison of hematologic values and transforming growth factor- $\beta$ and insulin like growth factor concentrations in platelets concentrates obtained by use of buffy coat and apheresis methods from equine blood. Am J Vet Res 65, 924-930.

Sutter WW. 2007. Autologous cell-based therapy for tendon and ligament injuries. Clin Tech Equine Pract 6, 198-208.

te Boekhorst PA, EA Beckers, MC Vos, H Vermeij, DJ van Rhenen. 2005. Clinical significance of bacteriologic screening in platelet concentrates. Transfusion 45, 514-519.
Walther-Wenke G, R Doerner, T Montag, O Greiss, B Hornei, R Knels, J Strobel, P Volkers, W Däubener. 2006. Bacterial contamination of platelet concentrates prepared by different methods: results of standardized sterility testing in Germany. Vox Sang 90, 177-182.

Waselau M, WW Sutter, RL Genovese, AL Bertone. 2008. Intralesional injection of platelet-rich plasma followed by controlled exercise for treatment of midbody suspensory ligament desmitis in Standardbred racehorses. J Am Vet Med Assoc 232, 1515-1520.

Zubrod CJ, KD Farnsworth, JL Oaks. 2004. Evaluation of arthrocentesis site bacterial flora before and after 4 methods of preparation in horses with and without evidence of skin contamination. Vet Surg $33,525-530$. 